Article

\title{
Understanding the Social and Emotional Wellbeing of Aboriginal LGBTIQ(SB)+ Youth in Victoria's Youth Detention
}

\author{
Péta Phelan ${ }^{1, *}$ and Robyn Oxley ${ }^{2}$ \\ ${ }^{1}$ Melbourne Poche Centre for Indigenous Health, University of Melbourne, Carlton, VIC 3010, Australia; \\ E-Mail: p.phelan@unimelb.edu.au \\ ${ }^{2}$ Criminology Department, School of Social Sciences, University of Western Sydney, Liverpool, NSW 2170, Australia; \\ E-Mail: r.oxley@westernsydney.edu.au \\ * Corresponding author
}

Submitted: 23 October 2020 | Accepted: 7 January 2021 | Published: 15 April 2021

\begin{abstract}
Aboriginal youth are overrepresented within Victoria's criminal justice system (Cunneen, 2020). Aboriginal and Torres Strait Islander youth are diverse people with diverse needs: It is imperative to understand what those needs are and how they can be supported within Victoria's youth justice centres. Research has identified that Aboriginal youth in Victoria's justice system have higher rates of psychopathology (Shepherd et al., 2018), higher rates of recidivism (Cunneen, 2008), higher pre-custody rates and post-release rates of substance abuse (Joudo, 2008) and lower rates of rehabilitation (Thompson et al., 2014) than non-Indigenous counterparts. It is critical to explore how the Victorian youth justice system identifies and implements the provision of services that consider lesbian, gay, bisexual, transgender, intersex, queer, sistergirl and brotherboy (LGBTIQSB+) identities of Aboriginal youth in custody. This is because additional levels of systemic disadvantage, discrimination, stigma, and social exclusion that impact LGBTIQ+ youth specifically (Cunneen, Goldson, \& Russell, 2016) as well as Aboriginal identity, further compound and jeopardize the social and emotional wellbeing of those embodying intersectional identities. This article will examine the services available to Aboriginal LGBTIQSB+ youth in the Victorian criminal justice system. Aboriginal, Torres Strait Islander, Indigenous and First Nations People will be used interchangeably throughout this document.
\end{abstract}

\section{Keywords}

Aboriginal; colonisation; criminal justice; Indigenous; intersectionality; LGBTIQ; LGBTIQSB+; mental health; Queer; sexual health; social and emotional wellbeing; youth

\section{Issue}

This article is part of the issue "Young, Indigenous, LGBTIQ+: Understanding and Promoting Social and Emotional Wellbeing" edited by Karen Soldatic (Western Sydney University, Australia), Linda Briskman (Western Sydney University, Australia), William Trewlynn (BlaQ Aboriginal Corporation, Australia), John Leha (BlaQ Aboriginal Corporation, Australia), Corrinne Sullivan (Western Sydney University, Australia) and Kim Spurway (Western Sydney University, Australia).

(C) 2021 by the authors; licensee Cogitatio (Lisbon, Portugal). This article is licensed under a Creative Commons Attribution 4.0 International License (CC BY).

\section{Introduction}

The purpose of this article is to explore the services and/or programs for Aboriginal Lesbian, Gay, Bisexual, Transgender, Intersex, Queer, Sistergirl and Brotherboy (LGBTIQSB+) youth in Victoria's juvenile criminal justice system. Sistergirl and Brotherboy refer to Aboriginal and/or Torres Strait Islander People in the community who embody an assigned gender, however live partly or fully as male (Brotherboy) or female (Sistergirl; see Anae, 2020). This article provides a background into the overrepresentation of Aboriginal youth in the Victorian youth justice system as well as an overview of the historical context and the impact of colonisation. The inclusion of Aboriginal youth within the Royal Commission into Aboriginal Deaths in Custody (RCIADIC) report 
and recommendations, and the latest strategic plan in Victoria with aims to address overrepresentation and reduce offending rates of youth will also be examined. The article will explore the importance of social and emotional wellbeing in Aboriginal cultures, mental health, intersectionality and servicing the needs of Aboriginal LGBTIQSB+ youth throughout the Victorian juvenile and criminal justice system. The authors of this article have deliberately chosen the literature, where possible, to cite Aboriginal scholarly work and centre lived experiences of Aboriginal and/or Torres Strait Islander LGBTIQSB+ people. The conscious decision to undertake this methodological approach prioritises sovereignty of this topic.

\section{Background}

Aboriginal and/or Torres Strait Islander People are overrepresented throughout the Australian criminal justice system in every State and Territory (Behrendt, Cunneen, Libesman, \& Watson, 2019; Blastock, Bamblett, \& Black, 2020). According to the Australian Institute of Health and Welfare (AlHW, 2018, p. 3) in 2016, Aboriginal and/or Torres Strait Islander young people, aged between 10 to 24 years of age, made up around $5 \%$ of the total Australian youth population. The report states that "of these, around 36\% were aged 10-14, 34\% were aged 15-19 and 30\% were aged 20-24" (AlHW, 2018, p. 3). In Victoria, Aboriginal youth comprised $1.3 \%$ of the total Victorian youth population (aged 10-17 years) in 2016, however, Aboriginal youth now make up $16.9 \%$ of all youth in detention (AlHW, 2020). Under the Sentencing Act 1991, Victoria operates a unique dual track system which was established to enable the adult courts to sentence young offenders under the age of 21 to serve their sentence in youth detention as opposed to an adult prison. The Victorian dual track system was designed to prevent young people from entering the adult prison system from an early age (Sentencing Advisory Council, 2019).

Aboriginal and/or Torres Strait Islander LGBTIQSB+ young people in Victoria who are in youth detention or custody may require particular medical or accommodation considerations (Victorian Government, 2020). In order to ascertain the needs of Aboriginal and/or Torres Strait Islander LGBTIQSB+ needs, there must be inclusion of Aboriginal community-controlled organisations and youth justice health organisations. According to the Victorian Commission for Children and Young People (2016, pp. 54-57), Aboriginal children who are engaged with an Aboriginal community-controlled organisation will have better health and wellbeing outcomes with the continued connection to culture. If Aboriginal LGBTIQSB+ youth within the criminal justice system in Victoria are centred, and their needs are not just met but understood and respected, then serious progress must be made relevant to the level of care provided to these young people. When people identify as Aboriginal and LGBTIQ+ it is crucial that their needs be considered to ensure there is safety within the criminal justice system and access to specific services.

\section{Historical Context}

In order to understand the overrepresentation of Aboriginal and/or LGBTIQ+ children in youth justice, the rates of imprisonment for children and young people in Victoria will be examined as well as the historical context and relationship between the criminal justice system and Aboriginal and/or Torres Strait Islander LGBTIQSB+ youth. Victoria's first legislation in relation to enacting a Protection Act, the Aborigines Protection Act 1886, was established in 1886. This act allowed the Board for the Protection of Aborigines to control the lives of Aboriginal people through forcibly removing "half caste' Aboriginal children from missions and reserves to be assimilated into white society (AIATSIS, 2020). This specific Act was the beginning of what is now termed the Stolen Generations. Victoria was not the only state to enact such policies. In New South Wales, the Aborigines Protection Act 1909 gave power to the Board of Protection to remove children from families and place them into white families to be assimilated (Cunneen \& White, 2011). Over the next few decades, Aboriginal protection policies and racist legislation that forcibly removed children from their families and communities continued well into the 1970s (Barta, 2008). The RCIADIC sparked a much-needed investigation into the overrepresentation of Aboriginal and/or Torres Strait Islander people within the criminal justice system (Cunneen, 2001). According to Cunneen (2020), there was difficulty in accessing appropriate data and statistics in relation to young people, however, there was a sense that the overrepresentation of Aboriginal young people was increasing. Cunneen (2020, p. 13) also notes that "it has only been since 1993 that national information has been available on incarcerated youth which identifies whether a young person is Indigenous or not." Given this to be the case, it must be assumed that information on LGBTIQ+ youth would be as difficult to obtain.

Identifying as Aboriginal and/or Torres Strait Islander and a young queer person impacts greatly on policing practices. There is a great deal of research into policing methods towards young LGBTIQ+ youth as well as the policing of Aboriginal youth (Cunneen, Goldson, \& Russell, 2016; Dwyer, 2011). Aboriginal youth are often targeted by police and policing practices. The misuse of police discretion in relation to Aboriginal youth as well as specific taskforces where Aboriginal children are constantly under the surveillance by police is presently occurring in communities throughout Australia (Cunneen, 2015; White, 1999). For LGBTIQ+ youth, the surveillance usually commences within the school and may result in criminal sanction and/or punishment (Snapp, Hoenig, Fields, \& Russell, 2015). In a paper by Angela Dwyer (2015), LGBTIQ+ youth were found to have learnt from interactions with police, firstly not to draw 
attention to their queerness, and, secondly to evade police by changing their appearance so as not to appear queer. The same cannot be said for Aboriginal youth, as their appearance is used as a racially profiling practice by police and is a contributing factor in the overrepresentation of Aboriginal people, in general, within the criminal justice system (Cunneen, 2006). The types of policing methods in relation to Aboriginal and LGBTIQ+ youth have impacted on the overrepresentation of these populations within youth justice. A robust examination of the appropriate and broad-ranging services available for Aboriginal LGBTIQSB+ youth within the criminal justice system, those that identify and meet the diverse needs of this population, must be undertaken. The psychological distress and harm of incarcerating Aboriginal LGBTIQSB+ young people have detrimental effects on their social and emotional wellbeing, continues the cycle of incarceration well in adulthood, and impacts not only the individual but also upon their family and community (Gee, Dudgeon, Schultz, Hart, \& Kelly, 2014). Alternatives to incarceration must be explored as well as services that adequately respond to the needs of Aboriginal LGBTIQSB+ children and young people.

\section{The Royal Commission into Aboriginal Deaths in Custody}

The RCIADIC was established in October 1987 due to a public growing concern regarding 99 Aboriginal deaths that occurred between 1980 and 1989 (RCIADIC, 1991). In 1991, the RCIADIC made 339 recommendations in relation to a range of criminal justice, health, education, housing, employment, and social systemic issues (Whittaker, 2018). There were 20 of the 339 recommendations made that related to youth or juvenile from the RCIADIC. One of the most prominent recommendations made in the report, highlights the urgency in reducing the overrepresentation of Aboriginal people in criminal and welfare systems, particularly young Aboriginal people:

That governments and Aboriginal organisations recognise that the problems affecting Aboriginal juveniles are so widespread and have such potentially disastrous repercussions for the future that there is an urgent need for governments and Aboriginal organisations to negotiate together to devise strategies designed to reduce the rate at which Aboriginal juveniles are involved in the welfare and criminal justice systems and, in particular, to reduce the rate at which Aboriginal juveniles are separated from their families and communities, whether by being declared to be in need of care, detained, imprisoned or otherwise. (RCIADIC, 1991, Vol. 2, p. 225)

Yet almost 30 years since the RCIADIC delivered its report and 339 recommendations, Aboriginal youth continue to be overrepresented throughout each Australian State or
Territory criminal justice systems. On any given day in the Northern Territory, Aboriginal children tend to make up $100 \%$ of youth in detention (Allam, 2020). As previously mentioned, in Victoria the statistics for Aboriginal youth are just as alarming, given the small percentage from the total population of Aboriginal youths in Victoria.

Since the RCIADIC, there has been a separate Royal Commission that focused on the treatment of children in detention in the Northern Territory. The Royal Commission and Board of Enquiry into the Protection and Detention of Children in the Northern Territory report and recommendations were tabled in Parliament in 2017 (Whittaker, 2018). The findings from this royal commission conveyed that the use segregation and isolation as a behavioural management tool had ongoing psychological effects on individuals (Grant, 2016). A submission into the inquiry of youth justice centres in Victoria (Naylor, Grant, \& Lulham, 2017), found that similar treatment of children and young people in youth justice centres was occurring in the Northern Territory, Queensland, and New South Wales. Although the Royal Commission into the detention and protection of children in the Northern Territory was conducted in and on children and young people in the Northern Territory, the findings from the report and recommendations can be applied to the treatment of children and young people in Victoria and across Australia; particularly Aboriginal and LGBTIQ+ children and young people. It is important to examine the rhetoric of the criminal justice system in relation to Royal Commissions and the report and recommendations that result from the investigations undertaken by the commissioners.

\section{The Youth Justice Strategic Plan 2020-2030}

The Youth Justice Strategic Plan 2020-2030 was established in May 2020 to reduce youth offending and promote working together with other justice agencies to meet the needs of children and young people in Victorian youth justice centres (Victorian Government, 2020). A thematic analysis was performed on the Youth Strategic Plan 2020-2030 document to examine the representation of LGBTIQ+ youth as well as Aboriginal youth. It is rarely seen in any documents on justice related outcomes, that intersectionality exists within the space of Aboriginal LGBTIQSB+ youth, therefore, the thematic analysis explored sections of Aboriginal, Torres Strait Islander, Indigenous, LGBTIQ(+), sexuality, youth, young people/person, juvenile, mental health, social and emotional wellbeing.

A thematic analysis (Merton, 1975) was employed to identify the number of times certain words were used throughout the Victorian Youth Strategic Plan 2020-2030. It is necessary to examine whether a pattern or whether a repetition of words was presented within the document to show where the priorities are in relation to Aboriginal LGBTIQ children and young people. To give a brief overview, Aboriginal was mentioned 84 
times, LGBTIQ was mentioned 14 times, mental health was mentioned 49 times, wellbeing was mentioned nine times and social and emotional wellbeing was mentioned only once, throughout the 53-page document. Addressing overrepresentation of Aboriginal LGBTIQSB+ youth within the juvenile justice system in Victoria, it was necessary to undertake this analysis to form part of the critique that Victoria's criminal justice system has not progressed enough to efficiently deal with the diverse needs of this particularly unique group of children and young people. The thematic analysis found the notable absence of Aboriginal LGBTISQ+ youth. For example, when explaining how youth justice will address the needs of LGBTIQ+ youth, there is simple statements is to "work with" and "collaborative with" (Victorian Government, 2020, p. 34). The language shown here is passive and any details as to whether there will be specific programs implemented or any connection to outside support groups is not mentioned.

As for Aboriginal youth, the 84 mentions indicate that there must be significant support mechanisms in place to support Aboriginal young people in youth justice. This is evident in the statistics and overrepresentation faced by Aboriginal children and young people. From the 84 mentions, five of the mentions are in the acknowledgement section (Victorian Government, 2020, p. 2). The following is from the Minister's Foreword, which states:

A disproportionate number of these young people are Aboriginal Victorians or members of culturally and linguistically diverse communities. (Victorian Government, 2020, p. 4)

There are two pages in this document that relate to Aboriginal youth. On those pages, exists a border consisting of Aboriginal artwork. Fredericks (2010) states in relation to feminist research, there is an element of tokenism when asking or expecting an Aboriginal person to be engaging in culture through a Western lens. The Western lens, in this case is the criminal justice system, whereby the idea of what Aboriginal culture is, can be seen in artwork in a document or hanging up on the wall of a courtroom, when in fact, this is simply not the case. There is an assumption by the western legal system that Aboriginal culture is a monoculture (Westerman, 2010). The displayed Aboriginal artwork within this document is tokenistic, as it ignores a true representation or understanding of what Aboriginal culture actually entails. Aboriginal culture is represented as dots and lines, rather than a deeper meaning of connection to country, to kin and to language.

In order to address the overrepresentation and explore that "the overrepresentation of Aboriginal young people in Youth Justice is unacceptably high and is an ongoing concern" (Victorian Government, 2020, p. 22), the system must link Aboriginal LGBTIQ+ youth to external services in order to make well-considered connections and establish meaningful relationships on the 'outside,' while they are on the 'inside.' Success in meaningful partnerships between community and the criminal justice system has been observed from programs in NSW, such as the "Never Going Back" program, where Aboriginal people in prison on day release from prison engage with the community, whereby upon release, they have already made strong connection with community (People DAA, 2016). Furthermore, the only time that Aboriginal and LGBTIQ+ are mentioned in the same sentence is in the following statement which calls for an awareness of individual needs, noting the need to:

Deliver individualised services that are cognisant of young people's age, gender, Aboriginal status, cultural background, family circumstances, health, mental health, disability and social needs, and sexuality and gender identity. (Victorian Government, 2020, p. 16)

From the thematic analysis, the above statement conveys that there is a lack of understanding around intersectionality, specifically when it comes to considering the children and young people who identify as Aboriginal LGBTIQSB+ within the criminal justice system. Given the issues that Aboriginal young people face within the criminal justice system, particularly with over-policing and surveillance of Aboriginal young people, intersectionality should be given more recognition and prioritised to reduce the interactions with the criminal justice system. There is a missed opportunity to engage with this particular group of young people throughout this strategic plan, which is further shown by the absence of services provided by Victorian corrections within youth justice to adequately meet the unique intersectional needs and requirements of Aboriginal LGBTIQ+ young people. Social and emotional wellbeing programs or services for Aboriginal or LGBTIQ+ young people are also inadequately met, only being referenced once throughout the document, which stated:

This whole-of-system examination has been designed to: address issues that affect the cultural connectedness and social and emotional wellbeing of the young person. (Victorian Government, 2020, p. 23)

\section{Social and Emotional Wellbeing of Aboriginal People}

The terms social and emotional wellbeing (SEWB), mental health, mental health problems, mental illness, and mental condition and/or disorder are often used interchangeably and can be a source of confusion when discussing the psychological wellbeing of Aboriginal people. Social and emotional wellbeing is a multidimensional concept that encompasses a range of domains of health and wellbeing. The SEWB of individuals, families, and communities is influenced and impacted by a connection to body, mind, emotions, family and kinship, community, culture, land, and spirituality (Gee et al., 2014). 
Connection describes the experiencing and embodiment across these SEWB spheres throughout the lifespan; the nature of these connections will vary across people's lives according to the different needs of childhood, youth, adulthood, and older age. Disruption to connections across these domains generate poorer SEWB, whilst reanimating, strengthening, and healing promotion leads to increased SEWB (Gee et al., 2014).

For Aboriginal and Torres Strait Islander People, health is not defined by the physical wellbeing of an individual, but refers broadly to the social, emotional, and cultural wellbeing of the whole community (Gee et al., 2014). In contrast to the Western medical models founded in reductionist approaches to health, where theoretical and practice inclinations are oriented toward deficit-centring and pathologising (focused primarily on inadequacy, dysfunction, and disorder), SEWB is a broader concept where the emphasis instead is oriented toward holistic and inclusive individual and community paradigms of strength and wellbeing (DHS Vic, 2008).

\section{Mental Health Considerations in Aboriginal Populations}

Aboriginal people experience higher levels of psychological distress in contrast to any other group in Australia, with the historical and current impacts of colonisation having perpetuated and continuing to perpetuate devastating impacts on individuals and communities at every level. Practices encompassed include war, massacres, and genocide; dispossession, displacement, and forced relocation, protectionism, surveillance, and incarceration, loss of traditional lands and ecological destruction, intentional and unintentional spread of deadly diseases, assimilation, regulation of marriage, and removal of children, forced labour, slavery and stolen wages, banning of Indigenous languages, and eradication of social, cultural and spiritual practices (Doyle, 2011; Paradies, 2016). The continuous and pervasive influences of white and/or Eurocentric supremacy, and the consequent racism, marginalisation, social inequity, loss of culture and identity, and issues of transgenerational trauma on Aboriginal health and wellbeing are well recognised (Balaratnasingam et al., 2019; Shen et al., 2018).

Critical to the nature and prevalence of Aboriginal psychological ill-health is the unresolved grief, loss, and trauma, of past and present State and colonisermediated violence and oppression, including the continuation of deeply paternalistic and disempowering policies and practices that undermine and neglect selfdetermination and cultural sovereignty of Aboriginal peoples. These factors are paramount in the sustained presence of historical traumatic wounds, and in the generation and perpetuation of new and unceasing trauma for Aboriginal people:

The legacy of traumatic experiences and oppression sustained through ongoing colonisation has ensured that the injury experienced has not been given an opportunity or space to heal. Grief and loss have been felt deeply and in ways people were not able to effectively deal with; instead, they had to fight just to survive. The legacy of this unacknowledged trauma and unresolved grief has resulted in its internalisation and festering of wounds which have been labelled as dysfunctional behaviours of the individual and collective sufferers. (Sherwood, 2015, p. 1)

In the 2014-2015 National Aboriginal and Torres Strait Islander Social Survey (NATSISS), it was found that $29 \%$ of Aboriginal and Torres Strait Islander People reported a diagnosed mental health condition ( $25 \%$ of males and $34 \%$ of females). Young people were less likely to report mental health conditions (22\%) compared to those in older age groups (ranging from $30 \%$ to $35 \%$ ). Aboriginal and Torres Strait Islander people in non-remote areas reported mental health conditions (33\%) at twice the rate than those in remote locations (16\%; Australian Bureau of Statistics, 2016). A systemic review identifying the prevalence rates of psychiatric disorders in Australia's Indigenous populations (Black et al., 2015) revealed that major depressive disorder (4.3-51\%), mood disorders (7.7-43.1\%), post-traumatic stress disorder (14.2-55.2\%), anxiety disorders (17.2-58.6\%), substance dependence (5.9\%-66.2\%), alcohol dependence (21.4-55.4\%), and psychotic disorders (1.68-25\%) were most prevalent, although stated that there is limited evidence on the occurrence of psychiatric disorders for Indigenous people in the general community.

\section{Mental Health Considerations in LGBTIQ+ Populations}

LGBTIQ+ people face astonishing rates of mental health concerns compared to the non-LGBTIQ+ population, as a direct result of the prejudice, discrimination, stigma, harassment, and violence that LGBTIQ+ people face in their communities, both underpinned and perpetuated by rampant heteronormative and heterosexist attitudes and ideologies (Meyer, 2003). LGBTIQ+ people suffer significant health disparities, higher incidents of moderate to severe mental health issues such as depression, anxiety, and posttraumatic stress, self-harm, suicidality and suicide rates (particularly in trans youth), substance abuse, and comorbid mental health and substance abuse (Leonard \& Metcalf, 2014). Other important considerations are the high rates of poverty, higher rates of unemployment or unstable employment, homelessness, and increased probability of violent victimisation compared with heterosexual and cisgender peers (Carman, Bourne, \& Fairchild, 2020).

\section{Intersectional Considerations}

For Aboriginal and/or Torres Strait Islander LGBTIQ+ people, being both Indigenous and identifying as 
LGBTIQSB+ creates a unique experience where the extensive health and socioeconomic disparities identified are compounded (Uink, Liddelow-Hunt, Daglas, \& Ducasse, 2020). Further compounding occurs based on other attributes and identities such as gender (specifically girls and women), age, disability, and class, and for individuals whose identities and existential realities are more complex, the impacts on health and wellbeing are multiplied by however many of those identities lie at their core. The phenomena of overlapping minority status, intersectionality, theorises and acknowledges the combined impacts on an individual, or marginalised community, of racism, sexism, heterosexism, ableism, classism, and xenophobia (Crenshaw, 1990).

In relation to this article, Aboriginal and/or Torres Strait Islander LGBTIQSB+ youth who are also involved in the criminal justice system have a multitude of complex forces compounding and impacting on their lives and their mental health continuously. Add to this, the high proportion of Aboriginal youth (AIHW, 2019) in detention who have a disability (Frize, Kenny, \& Lennings, 2008) and those who are girls/young women and it becomes much more apparent the level of vulnerability this particular population embody, and the complex mental health and cultural services required to appropriately meet their health, wellbeing, and safety needs.

\section{Youth Mental Health}

Adolescence is a vulnerable period for youth with a range of biological, interpersonal, cognitive, environmentalecological changes and life transitions taking place, and an increase in the occurrence of stressful life events and adaptive functioning required. For those with mental health concerns and conditions, the stress can be persistent, disruptive, and all-consuming. For youth who are under the scrutiny of the criminal justice system, the additional high-level physical and psychological stress associated can be overwhelming and incredibly harmful (The Royal Australasian College of Physicians, 2011).

Adolescence is understood to be a pivotal phase for the development of psychological ill-health, with evidence supporting that the presence of psychopathology in adolescence is a risk factor for psychopathology and subsequent long-term dysfunction into adulthood (Sheffield, Fiorenza, \& Sofronoff, 2004). Addressing it during this vulnerable time may prevent or minimise the impacts on the social and emotional wellbeing of young people as they mature.

\section{Mental Health Help-Seeking}

Attitudes towards help-seeking play an important role in the willingness to seek professional psychological assistance and has been shown to be a significant predictor of intentions and motivation to seek help for personal problems and psychological concerns, including suicidal ideation (Carlton \& Deane, 2000). Barriers to help-seeking behaviours in youth populations generally include factors such as stigma and negative perceptions around mental health conditions, concerns around what others may think, reduced access due to cost, poor mental health literacy, uncertainty of where to seek help, lack of trust in mental health systems and/or professionals and concerns of confidentiality, hopelessness, and preference for self-reliance (Gulliver, Griffiths, \& Christensen, 2010; Velasco, Santa Cruz, Billings, Jimenez, \& Rowe, 2020). These factors are consistent with what is found in Aboriginal and LGBTIQ+ youth populations, however additional barriers to mental health help-seeking exist within these groups (Brown, Rice, Rickwood, \& Parker, 2016).

Other barriers specific to Aboriginal youth populations in help-seeking for mental health issues include discrimination, intergenerational stigma and feelings of shame associated with help-seeking particularly regarding mental illness (Price \& Dalgleish, 2013), concerns regarding confidentiality and being misunderstood (Adermann and Campbell, 2007), fear of potential ramifications such as government intervention and being ostracised by community (Lumby \& Farrelly, 2009), a lack of availability of culturally-safe services, geographic isolation for Aboriginal people living in rural and remote communities, and poor-help seeking experiences in the past. It is also important to note that cultural paradigms and conceptualisations of mental illness, and what defines a mental health problem, are often distinct and antithetical to Western conceptualisations of psychological health and mental illness.

LGBTIQ+ youth also experience additional barriers (Kilicaslan \& Petrakis, 2019; Williams \& Chapman, 2011; Wilson \& Cariola, 2020) to help-seeking and in accessing mental health assistance, including discrimination and lack of LGBTIQ+ culturally appropriate and safe services (McNair \& Bush, 2016), fear of stigmatisation, shame, and embarrassment (Brown et al., 2016). LGBTQI+ youth who are homeless, rural, or who are substance-users face additional barriers to seeking help (Brown et al., 2016).

\section{Aboriginal LGBTIQSB+ Youth in Detention}

Within Australia there is a considerable gap in the literature around the policy approaches, prevalence, nature, and therapeutic frameworks and practices of mental health and wellbeing within youth criminal justice populations, and even less so when it comes to looking at any of these areas from an Aboriginal and/or Torres Strait Islander youth and LGBTIQ+ youth perspective. As far as examining the experiences and requirements of Aboriginal and/or Torres Strait Islander LGBTIQSB+ youth within detention in Australia, there was no academic literature to be found. Internationally, there is some literature that addresses LGBTIQ+ youth populations' experiences within the justice system (Jonnson, Bird, Li, \& Viljoen, 2019; Mountz, 2020; Irvine, 2010; Trimble, 2019; Wilson et al., 2017), and others that address both racial and LGBTIQ+ identity (Alvarez, 2020; Hovey, Zolkoski, \& 
Bullock, 2017) within youth justice systems, however research addressing the intersectional understanding and nuance between Indigeneity, LGBTIQ+ identity, and youth experiences in relation to the justice system and mental health servicing is scant.

Adolescents who commit serious offences experience a wide range of psychosocial challenges, as well as reduced educational, occupational, and social opportunities (Melton \& Pagliocca, 1992). The mental health requirements and care of all adolescents involved with the juvenile criminal justice system requires considerable attention and prioritisation. A range of studies (Bickel \& Campbell, 2002; Kosky, Sawyer, \& Fotheringham, 1996; Teplin, Abram, McClelland, Dulcan, $\&$ Mericle, 2002) have recognised, even after excluding conduct disorder, the "higher prevalence of mental health disorders and behavioural problems among young people in the youth justice system when compared with the general population, with rates of up to $75 \%$ reported to fulfil the criteria for one or more diagnosable psychiatric disorders" (The Royal Australasian College of Physicians, 2011, p. 17). Within this population, research shows alarming rates of self-harm, suicidal ideation and suicide, substance abuse, major depression and chronic dysthymia, anxiety disorders, and posttraumatic stress, as well as high rates of attention-deficit/hyperactivity disorder and autism (Shepherd, Spivak, Borschmann, Kinner, \& Hachtel, 2018; Stathis \& Martin, 2004). There is also expanding evidence that suggests a significant comorbidity between substance abuse and mental health issues exists within this group, with notable comorbidity between drug use and drug-induced psychosis (Degenhardt et al., 2015). Based upon data regarding the elevated prevalence, nature, and severity of mental health and wellbeing concerns in Aboriginal and LGBTIQ+ populations as outlined above, it can be assumed that Aboriginal LGBTIQSB+ youth in detention are an incredibly vulnerable population with critical mental health considerations, whose social and emotional wellbeing requirements must be appropriately prioritised and advanced.

Of particular concern for the health and social and emotional wellbeing of Aboriginal LGBTIQSB+ youth within detention, is the absence of specific recognition and protection of their rights within the juvenile justice system in Australia based upon their LGBTIQ+ status; a case meticulously dissected and articulated by Richards and Dwyer (2014). Although there are a number of international human rights frameworks that protect the rights of young people engaged with the criminal justice system, frameworks that inform the Australasian Juvenile Justice Administrators (AJJA) and from where the AJJA draw their national standards, the LGBTIQ+ status of young people has been explicitly excluded from the list of protected attributes. This omission has considerable implications for national and state-based policies, practices, and standards that shape youth justice, effectively erasing LGBTIQ+ youth from all consideration.

\section{Servicing the Needs of Aboriginal LGBTIQSB+ Youth}

Historically, the disciplines of psychiatry and psychology and the health professionals and researchers who practiced in and around these spheres (including but not exclusive to psychiatrists, psychologists, mental health nurses, and social workers) have done inexplicable harm to both Aboriginal populations and the LGBTIQ+ community (Carr \& Spandler, 2019; Gone, 2013; Harms et al., 2011). Within an Australian context, Aboriginal and/or Torres Strait Islander and LGBTIQ+ people have been problematised and pathologized by these professional communities (Askew, Lyall, Ewen, Paul, \& Wheeler, 2017; Bond \& Brady, 2013) lending scientific legitimacy to the broader labelling, cultural stereotyping and stigmatisation of Aboriginality and minority sexualities and genders, promulgating and maintaining social validity for widespread practices of exclusion, oppression, violence, and criminalisation (Kenny, 2014; Sweet, Musulin, McCallum, \& Geia, 2016).

Although health professions have made good progress in this space by aligning professional education, ethics and practices with legal requirements around anti-discrimination law and diversity practices (Ewen \& Hollinsworth, 2016), much of the pathologising, stigmatisation, and coercive corrective practices still exist through conscious and unconscious racism and heterosexism, both founded in and perpetuated by a culturally white (Eurocentric) heteronormative ideology (van der Toorn, Pliskin, \& Morgenroth, 2020; Wilson et al., 2017). These attitudes and practices deeply impact the likelihood for help-seeking behaviour, motivation to participate in sustained therapeutic engagement, success of therapeutic approaches, potentiality for recovery, or successful corrective rehabilitation evidenced by lack of recidivism.

Mental health supports and therapeutic approaches for Aboriginal and/or Torres Strait Islander LGBTIQSB+ youth in detention, must be those that promote and prioritise the specific and unique cultural needs of both their Aboriginality and their sexuality and/or gender identity. A multidisciplinary approach to social and emotional wellbeing must be social model oriented rather than biomedically reductionist, culturallycentred, and strengths-based (Cunneen, 2018; Durey, Wynaden, Barr, \& Ali, 2014; Whitton \& Indig, 2012), and, not wholly or explicitly directed and/or moderated by a Western medical paradigm with psychiatry at the helm. The current mental health practice models within Australian youth justice centres do not support any progress toward a culturally-appropriate and robustly intersectional approach for Aboriginal and/or Torres Strait Islander LGBTIQSB+ youth, in part due to the dearth of culturally-aligned and culturally-validated evidence based screening and assessment tools, outcomes measures, and therapeutic approaches (Singh, Kasinathan, \& Kennedy, 2017; Stathis, Harden, Martin, \& Chalk, 2013; Stathis et al., 2008). 


\section{Conclusion}

This article provides a foundational exploration and understanding of the social and emotional wellbeing needs of Aboriginal and/or Torres Strait Islander LGBTIQSB+ youth engaged with the criminal justice system in Victoria. As far as the authors are aware, it is also the first to do so across any Australian jurisdiction. Based upon critical engagement with the literature and the findings presented throughout, the social and emotional wellbeing needs of Aboriginal and/or Torres Strait Islander LGBTIQSB+ youth in detention must be prioritised and serviced by a more meaningful engagement with services and/or programs that adequately meet and respond to Aboriginal and/or Torres Strait Islander LGBTIQSB+ needs-those that prioritise and centre intersectionality. This includes a more nuanced and holistic understanding and interpretation of international human rights law and frameworks as it applies to youth in detention by the AJJA, with specific inclusion of LGBTIQ+ in anti-discrimination policies and procedures within the national standards and framework, to be both disseminated and upheld throughout each jurisdiction in Australia. The use of language, and the inclusion of LGBTIQSB+ lived experiences within the youth justice frameworks would need to be extended to centre those voices with lived experiences of being an Aboriginal and/or Torres Strait Islander LGBTIQSB+ individual, as the centred voices encompass a depth of cultural knowledge; particularly important when exploring the methodological and ethical issues associated with researching within Aboriginal and/or Torres Strait Islander spaces (Holt, 2004). Prioritised engagement of Aboriginal and/or Torres Strait Islander LGBTIQSB+ health and social and emotional wellbeing services that centre self-determination and ensure that programs and/or services are designed, directed, and delivered by Aboriginal and/or Torres Strait Islander LGBTIQSB+ people must also be acutely considered.

As a final note, Grisso (1999) proposes that a punitive trend in juvenile justice in a number of jurisdictions (leading to an elevated number of youths becoming incarcerated) is providing a promising academic landscape for researchers interested in psychological spheres of criminology and youth justice, presenting opportunities and "unexpected resources...to learn more about mental illnesses among youthful offenders than we have known before" (Grisso, 1999, p. 150). What must be avoided at all costs, particularly when considering Aboriginal and/or Torres Strait Islander LGBTIQSB+ youth engaged with the criminal justice system, and especially by non-Indigenous and non-LGBTIQ+ researchers, is the exploitation, harvesting, adapting, or reproducing of narratives, knowledges, and experiences of these highly vulnerable groups to promote the researchers own academic and professional agendas, expertise, and reputational kudos.

\section{Acknowledgments}

We would like to acknowledge the tireless efforts from grassroots campaigning to ensure that the needs of Aboriginal LGBTIQSB+ children and young people are met in every capacity.

\section{Conflict of Interests}

The authors declare no conflict of interests.

\section{References}

Adermann, J., \& Campbell, M. (2007). Big worry: Implications of anxiety in Aboriginal youth. The Australian Journal of Aboriginal Education, 36, 74-80.

Allam, L. (2020, June 22). Northern Territory's new youth justice 'crackdown' will harm Aboriginal children, justice groups says. The Guardian. Retrieved from https://www.theguardian.com/australia-news/ 2020/jun/22/northern-territorys-new-youth-justicecrackdown-will-harm-aboriginal-children-justicegroups-say

Alvarez, J. (2020). Healing LGBTQ+ juvenile youth of color through Indigenous practices (Unpublished Masters dissertation). University of San Francisco, California, USA. Retrieved from https://repository.usfca.edu/ cgi/viewcontent.cgi?article $=2375 \&$ context $=$ thes

Anae, N. (2020). "Embracing what is rightfully ours": Representing Australian Aboriginal Brotherboy identities. European Journal of English Studies, 24(1), 76-88.

Askew, D. A., Lyall, V. J., Ewen, S. C., Paul, D., \& Wheeler, M. (2017). Understanding practitioner professionalism in Aboriginal and Torres Strait Islander health: Lessons from student and registrar placements at an urban Aboriginal and Torres Strait Islander primary healthcare service. Australian Journal of Primary Health, 23(5), 446-450.

Australian Bureau of Statistics. (2016). National Aboriginal and Torres Strait Islander social survey, 2014-15. (No. 4714.0). Australian Bureau of Statistics. Retrieved from http://tiny.cc/dci8tz

AIATSIS. (2020). Victoria: Legislation/key provisions. Canberra: Australian Institute of Aboriginal and Torres Strait Islander Studies. Retrieved from https:// aiatsis.gov.au/collection/featured-collections/ remove-and-protect/victoria

Australian Institute of Health and Wellbeing. (2018). Aboriginal and Torres Strait Islander adolescent and youth health and wellbeing. Canberra: Australian Institute of Health and Wellbeing. Retrieved from https://www.aihw.gov.au/getmedia/e9434481c52b-4a79-9cb5-94f72f04d23e/aihw-ihw-198.pdf. aspx?inline=true

Australian Institute of Health and Welfare. (2019). Youth detention population in Australia. Canberra: Australian Institute of Health and Wellbeing. Retrieved from https://www.aihw.gov.au/getmedia/ 
c3ba6d29-7488-4050-adae-12d96588bc37/aihw-

juv-131.pdf.aspx?inline=true

Australian Institute of Health and Wellbeing. (2020). Youth justice in Australia. Canberra: Australian Institute of Health and Wellbeing. Retrieved from https://www.aihw.gov.au/getmedia/a5a364b9-fe694d02-9c93-1965a69a3d93/aihw-juv-132.pdf.aspx? inline=true

Balaratnasingam, S., Chapman, M., Chong, D., Hunter, E., Lee, J., Little, C., . . . Janca, A. (2019). Advancing social and emotional well-being in Aboriginal and Torres Strait Islander Australians: Clinicians' reflections. Australasian Psychiatry, 27(4), 348-351.

Barta, T. (2008). Sorry, and not sorry, in Australia: How the apology to the stolen generations buried a history of genocide. Journal of Genocide Research, 10(2), 201-214.

Behrendt, L., Cunneen, C., Libesman, T., \& Watson, N. (2019). Aboriginal and Torres Strait Islander legal relations. Oxford: Oxford University Press.

Bickel, R., \& Campbell, A. (2002). Mental health of adolescents in custody: The use of the 'adolescent psychopathology scale' in a Tasmanian context. Australian \& New Zealand Journal of Psychiatry, 36(5), 603-609.

Black, E. B., Ranmuthugala, G., KondalsamyChennakesavan, S., Toombs, M. R., Nicholson, G. C., \& Kisely, S. (2015). A systematic review: Identifying the prevalence rates of psychiatric disorder in Australia's Indigenous populations. Australian \& New Zealand Journal of Psychiatry, 49(5), 412-429.

Blastock, C., Bamblett, M., \& Black, C. (2020). Indigenous ontology, international law and the application of the Convention to the over-representation of Indigenous children in out of home care in Canada and Australia. Child Abuse \& Neglect, 110. https://doi.org/10.1016/ j.chiabu.2020.104587

Bond, C., \& Brady, K. (2013). Locating Indigenous Australia within community development practice: Clients, consumers or change makers? New Community, 11(43), 33-39.

Brown, A., Rice, S. M., Rickwood, D. J., \& Parker, A. G. (2016). Systematic review of barriers and facilitators to accessing and engaging with mental health care among at-risk young people. Asia-Pacific Psychiatry, 8(1), 3-22.

Carlton, P. A., \& Deane, F. P. (2000). Impact of attitudes and suicidal ideation on adolescents' intentions to seek professional psychological help. Journal of Adolescence, 23(1), 35-45.

Carman, M., Bourne, A., \& Fairchild, J. (2020). COVID-19 impacts for LGBTIQ communities and implications for services. Melbourne: Rainbow Health Victoria. Retrieved from https://rainbowhealthvic.org.au/ media/pages/research-resources/research-briefingpapercovid-19-impacts-for-Igbtiq-communitiesand-implications-for-services/817379592--- 1586396368/rainbow-health-victoria-researchbriefing-paper-covid-19.pdf

Carr, S., \& Spandler, H. (2019). Hidden from history? A brief modern history of the psychiatric "treatment" of lesbian and bisexual women in England. The Lancet Psychiatry, 6(4), 289-290.

Crenshaw, K. (1990). Mapping the margins: Intersectionality, identity politics, and violence against women of color. Stanford Law Review, 43, 1241-1299.

Cunneen, C. (2001). Assessing the outcomes of the Royal Commission into Aboriginal Deaths in Custody. Health Sociology Review, 10(2), 53-64.

Cunneen, C. (2006). Racism, discrimination and the overrepresentation of Indigenous people in the criminal justice system: Some conceptual and explanatory issues. Current Issues in Criminal Justice, 17(3), 329-346.

Cunneen, C. (2008). Changing the neo-colonial impacts of juvenile justice. Current Issues in Criminal Justice, 20(1), 43-58.

Cunneen, C. (2015). Surveillance, stigma, removal: Indigenous child welfare and juvenile justice in the age of neoliberalism. Australian Indigenous Law Review, 19(1), 32-45.

Cunneen, C. (2018). Self-determination and the Aboriginal youth justice strategy. Sydney: University of Technology.

Cunneen, C. (2020). Conflict, politics and crime: Aboriginal communities and the police. London and New York, NY: Routledge.

Cunneen, C., Goldson, B., \& Russell, S. (2016). Juvenile justice, young people and human rights in Australia. Current Issues in Criminal Justice, 28(2), 173-189.

Cunneen, C., \& White, R. (2011). Juvenile justice: Youth and crime in Australia. Oxford: Oxford University Press.

Degenhardt, L., Coffey, C., Hearps, S., Kinner, S. A., Borschmann, R., Moran, P., \& Patton, G. (2015). Associations between psychotic symptoms and substance use in young offenders. Drug and Alcohol Review, 34(6), 673-682.

DHS Vic. (2008). Headline indicators for children's health, development and wellbeing. Melbourne: Australian Health Ministers' Conference and the Community and Disability Services Ministers' Conference.

Doyle, K. (2011). Modes of colonisation and patterns of contemporary mental health: Towards an understanding of Canadian Aboriginal, Australian Aboriginal and Maori peoples. Aboriginal and Islander Health Worker Journal, 35(1), 20-24.

Durey, A., Wynaden, D., Barr, L., \& Ali, M. (2014). Improving forensic mental health care for Aboriginal Australians: Challenges and opportunities. International Journal of Mental Health Nursing, 23(3), 195-202.

Dwyer, A. (2011). Policing lesbian, gay, bisexual and transgender young people: A gap in the research literature. Current Issues in Criminal Justice, 22(3), 415-433.

Dwyer, A. (2015). Teaching young Queers a lesson: How 
police teach lessons about non-heteronormativity in public spaces. Sexuality \& Culture, 19(3), 493-512.

Ewen, S. C., \& Hollinsworth, D. (2016). "Unwell while Aboriginal": latrogenesis in Australian medical education and clinical case management. Advances in Medical Education and Practice, 7, 311-315.

Fredericks, B. (2010). Reempowering ourselves: Australian Aboriginal women. Signs: Journal of Women in Culture and Society, 35(3), 546-550.

Frize, M., Kenny, D., \& Lennings, C. (2008). The relationship between intellectual disability, Indigenous status and risk of reoffending in juvenile offenders on community orders. Journal of Intellectual Disability Research, 52(6), 510-519.

Gee, G., Dudgeon, P., Schultz, C., Hart, A., \& Kelly, K. (2014). Aboriginal and Torres Strait Islander social and emotional wellbeing. In P. Dudgeon \& R. Walker (Eds.), Working together: Aboriginal and Torres Strait Islander mental health and wellbeing principles and practice (pp. 55-68). Canberra: Commonwealth of Australia.

Gone, J. P. (2013). Redressing First Nations historical trauma: Theorizing mechanisms for Indigenous culture as mental health treatment. Transcultural Psychiatry, 50(5), 683-706.

Grant, E. (2016). The use of segregation for children in the Northern Territory Youth detention system: Submission to the Royal Commission into the Protection and Detention of Children in the Northern Territory. Adelaide: The University of Adelaide.

Grisso, T. (1999). Juvenile offenders and mental illness. Psychiatry, Psychology and Law, 6(2), 143-151. https://doi.org/10.1080/13218719909524956

Gulliver, A., Griffiths, K. M., \& Christensen, H. (2010). Perceived barriers and facilitators to mental health helpseeking in young people: A systematic review. BMC Psychiatry, 10(1). https://doi.org/10.1186/1471244X-10-113

Harms, L., Middleton, J., Whyte, J., Anderson, I., Clarke, A., Sloan, J., . . S Smith, M. (2011). Social work with Aboriginal clients: Perspectives on educational preparation and practice. Australian Social Work, 64(2), 156-168.

Holt, L. (2004). The 'voices' of children: De-centring empowering research relations. Children's Geographies, 2(1), 13-27.

Hovey, K. A., Zolkoski, S. M., \& Bullock, L. M. (2017). Mental health and the juvenile justice system: Issues related to treatment and rehabilitation. World Journal of Education, 7(3), 1-13.

Irvine, A. (2010). We've had three of them: Addressing the invisibility of lesbian, gay, bisexual, and gender nonconforming youths in the juvenile justice system. Columbia Journal of Gender \& Law, 19. https://doi. org/10.7916/cjgl.v19i3.2603

Jonnson, M. R., Bird, B. M., Li, S. M., \& Viljoen, J. L. (2019). The prevalence of sexual and gender minority youth in the justice system: A systematic review and meta-analysis. Criminal Justice and Behavior, 46(7), 999-1019.

Joudo, J. (2008). Responding to substance abuse and offending in Indigenous communities: Review of diversion programs. Canberra: Australian Institute of Criminology.

Kenny, D. T. (2014). Mental health concerns and behavioural problems in young offenders in the criminal justice system. Judicial Officers Bulletin, 26(4). Retrieved from https://ojjdp.ojp.gov/sites/g/ files/xyckuh176/files/pubs/242440.pdf

Kilicaslan, J., \& Petrakis, M. (2019). Heteronormative models of health-care delivery: Investigating staff knowledge and confidence to meet the needs of LGBTIQ+ people. Social Work in Health Care, 58(6), 612-632.

Kosky, R. J., Sawyer, M. G., \& Fotheringham, M. (1996). The mental health status of adolescents released from custody: A preliminary study. Australian and New Zealand Journal of Psychiatry, 30(3), 326-331.

Leonard, W., \& Metcalf, A. (2014). Going upstream: A framework for promoting the mental health of lesbian, gay, bisexual, transgender and intersex (LGBTI) people. Australia: National LGBTI Health Alliance.

Lumby, B., \& Farrelly, T. (2009). A best practice approach to cultural competence training. Aboriginal and Islander Health Worker Journal, 33(5), 14-22.

McNair, R. P., \& Bush, R. (2016). Mental health help seeking patterns and associations among Australian same sex attracted women, trans and gender diverse people: A survey-based study. BMC Psychiatry, 16(1). https://doi.org/10.1186/s12888-016-0916-4

Melton, G. B., \& Pagliocca, P. M. (1992). Treatment in the juvenile justice system: Directions for policy and practice. Responding to the mental health needs of youth in the juvenile justice system. In J. J. Cocozza (Ed.), Responding to the mental health needs of youth in the juvenile justice system (pp. 107-139). Seattle, WA: The National Coalition for the Mentally III in the Criminal Justice System Seattle.

Merton, R. K. (1975). Thematic analysis in science: Notes on Holton's concept. Science, 188(4186), 335-338.

Meyer, I. H. (2003). Prejudice, social stress, and mental health in lesbian, gay, and bisexual populations: Conceptual issues and research evidence. Psychological Bulletin, 129(5), 674-697. https://doi.org/10.1037/ 0033-2909.129.5.674

Mountz, S. (2020). Remapping pipelines and pathways: Listening to queer and transgender youth of color's trajectories through girls' juvenile justice facilities. Affilia, 35(2), 177-199.

Naylor, B., Grant, E., \& Lulham, R. (2017). The segregation and isolation of children and young people in Victorian Juvenile Justice: Rethinking a flawed system. Submission to Inquiry into Youth Justice Centres in Victoria. Melbourne: Parliament of Victoria.

Paradies, Y. (2016). Colonisation, racism and Indigenous health. Journal of Population Research, 33(1), 83-96. 
People DAA. (2016). Judicial officers are advised of the following Aboriginal services, programs and Ngara Yura seminars: Driving and licence offences project, NSW. Sydney: Judicial Officers Bulletin.

Price, M., \& Dalgleish, J. (2013). Help-seeking among indigenous Australian adolescents: Exploring attitudes, behaviours and barriers. Youth Studies Australia, 32(1), 10-18.

Richards, K., \& Dwyer, A. (2014). Unspeakably present: The (un)acknowledgment of diverse sexuality and gender human rights in Australian youth justice systems. Australian Journal of Human Rights, 20(2), 63-79.

Royal Commission into Aboriginal Deaths in Custody. (1991). Royal Commission into Aboriginal deaths in custody: Reports. Canberra: Australian Government Publishing Service. Retrieved from http://hdl.voced. edu.au/10707/54522

Sentencing Advisory Council. (2019). Sentence types for children and young people. Sentencing Council. Retrieved from https://www.sentencingcouncil. vic.gov.au/about-sentencing/sentence-types-forchildren-and-young-people

Sheffield, J. K., Fiorenza, E., \& Sofronoff, K. (2004). Adolescents' willingness to seek psychological help: Promoting and preventing factors. Journal of Youth and Adolescence, 33(6), 495-507.

Shen, Y. T., Radford, K., Daylight, G., Cumming, R., Broe, T. G., \& Draper, B. (2018). Depression, suicidal behaviour, and mental disorders in older Aboriginal Australians. International Journal of Environmental Research and Public Health, 15(3). https://doi.org/ 10.3390/ijerph15030447

Shepherd, S., Spivak, B., Borschmann, R., Kinner, S. A., \& Hachtel, H. (2018). Correlates of self-harm and suicide attempts in justice-involved young people. PLoS One, 13(2). https://doi.org/10.1371/journal. pone. 0193172

Sherwood, J. (2015). Intergenerational trauma isn't just another determinant of Indigenous People's health. Journal of Ethics in Mental Health, 7. Retrieved from https://jemh.ca/issues/v9/documents/JEMH_OpenVolume_Article_Theme_Colonization_ Intergenerational_Trauma_June2015.pdf

Singh, Y., Kasinathan, J., \& Kennedy, A. (2017). Incarcerated youth mental and physical health: Parity of esteem. International Journal of Human Rights in Healthcare, 10(3). https://doi.org/10.1108/IJHRH03-2017-0011

Snapp, S. D., Hoenig, J. M., Fields, A., \& Russell, S. T. (2015). Messy, butch, and queer: LGBTQ youth and the school-to-prison pipeline. Journal of Adolescent Research, 30(1), 57-82.

Stathis, S. L., Harden, S., Martin, G., \& Chalk, J. (2013). Challenges in establishing adolescent forensic mental health services within Australian youth detention centres. Psychiatry, Psychology and Law, 20(6), 899-908.
Stathis, S., Letters, P., Doolan, I., Fleming, R., Heath, K., Arnett, A., \& Cory, S. (2008). Use of the Massachusetts Youth Screening Instrument to assess mental health problems in young people within an Australian youth detention centre. Journal of Paediatrics and Child Health, 44(7/8), 438-443.

Stathis, S., \& Martin, G. (2004). A transdisciplinary approach to adolescent forensic mental health. Australian \& New Zealand Journal of Psychiatry, 38(9), 746-752.

Sweet, M., Musulin, K., McCallum, K., \& Geia, L. (2016). Acknowledge the brutal history of Indigenous health care-for healing. Croakey. Retrieved from https://croakey.org/acknowledge-the-brutalhistory-of-Indigenous-health-care-for-healing

Teplin, L. A., Abram, K. M., McClelland, G. M., Dulcan, M. K., \& Mericle, A. A. (2002). Psychiatric disorders in youth in juvenile detention. Archives of General Psychiatry, 59(12), 1133-1143.

The Royal Australasian College of Physicians. (2011). The health and well-being of incarcerated adolescents. Sydney: The Royal Australasian College of Physicians.

Thompson, C., Stewart, A., Allard, T., Chrzanowski, A., Luker, C., \& Sveticic, J. (2014). Examining adult-onset offending: A case for adult cautioning. Canberra: Australian Institute of Criminology.

Trimble, P. E. (2019). Ignored LGBTQ prisoners: Discrimination, rehabilitation, and mental health services during incarceration. LGBTQ Policy Journal. https:// Igbtq.hkspublications.org/2019/05/22/ignoredIgbtq-prisoners-discrimination-in-educationrehabilitative-and-mental-health-services-duringincarceration

Uink, B., Liddelow-Hunt, S., Daglas, K., \& Ducasse, D. (2020). The time for inclusive care for Aboriginal and Torres Strait Islander LGBTQ+ young people is now. The Medical Journal of Australia, 213(5). https://doi. org/10.5694/mja2.50718

van der Toorn, J., Pliskin, R., \& Morgenroth, T. (2020). Not quite over the rainbow: The unrelenting and insidious nature of heteronormative ideology. Current Opinion in Behavioral Sciences, 34, 160-165.

Velasco, A. A., Santa Cruz, I. S., Billings, J., Jimenez, M., \& Rowe, S. (2020). What are the barriers, facilitators and interventions targeting help-seeking behaviours for common mental health problems in adolescents? A systematic review. BMC Psychiatry, 20(1), $1-22$.

Victorian Commission for Children and Young People. (2016). Always was, always will be Koori Children: Systemic inquiry into services provided to Aboriginal children and young people in out-of-home care in Victoria. Victoria: Commission for Children and Young People.

Victorian Government. (2020). Youth justice strategic plan 2020-2030. Victoria: Victorian Government. Retrieved from https://www.justice.vic.gov.au/ sites/default/files/embridge_cache/emshare/ 
original/public/2020/06/89/79b442d3c/Youth-

Justice-Strategic-Plan.pdf

Westerman, T. (2010). Engaging Australian Aboriginal youth in mental health services. Australian Psychologist, 45(3), 212-222.

White, R. (1999). Indigenous youth and offensive spaces. Social Alternatives, 18(2). https://doi.org/10.1080/ 13676260120111742

Whittaker, A. (2018). The unbearable witness, seeing: A case for Indigenous methodologies in Australian soft law. Pandora's Box: Journal of Justice and the Law Society at the University of Queensland, 2018(25), 23-36.

Whitton, N., \& Indig, D. (2012). Improving aboriginal Juvenile detainees' access to community health ser- vices. Aboriginal and Islander Health Worker Journal, 36(1), 13-17.

Williams, K. A., \& Chapman, M. V. (2011). Comparing health and mental health needs, service use, and barriers to services among sexual minority youths and their peers. Health \& Social Work, 36(3), 197-206.

Wilson, B. D., Jordan, S. P., Meyer, I. H., Flores, A. R., Stemple, L., \& Herman, J. L. (2017). Disproportionality and disparities among sexual minority youth in custody. Journal of Youth and Adolescence, 46(7), 1547-1561.

Wilson, C., \& Cariola, L. A. (2020). LGBTQI+ youth and mental health: a systematic review of qualitative research. Adolescent Research Review, 5(2), 187-211.

\section{About the Authors}
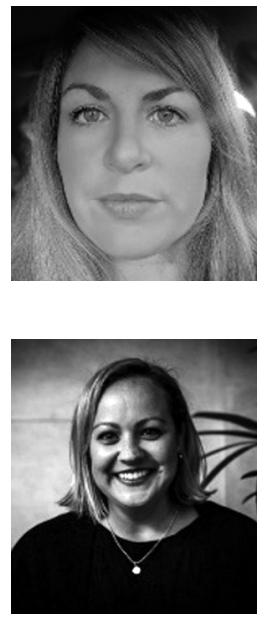

Péta Phelan is a Koori woman with family connections to Deniliquin in the Riverina region of south western New South Wales. She is a professional rehabilitation counsellor employed with the University of Melbourne in the Poche Centre for Indigenous Health in the Faculty of Medicine, Dentistry and Health Science. Péta has a Masters of Rehabilitation Counselling where she focused on mental health and psychological injuries, and is currently undertaking a PhD at the University of Melbourne where her research centres broadly across Aboriginal LGBTIQSB+ identities, gender, social and emotional wellbeing, and intersectional experiences of health accessibility and service delivery.

Robyn Oxley is a Tharawal woman and has family connections to Yorta Yorta. Robyn is an activist and a lecturer at Western Sydney University in Criminology. Her field is in the space of the criminal justice system and Aboriginal rights to self-determination. Her work primarily focuses on human rights, social justice, systemic racism and improving outcomes of Aboriginal people in relation to the criminal justice system. 